\title{
REFUGEE RESETTLEMENT IN AUSTRALIA: WHAT WE KNOW AND NEED TO KNOW \\ Farida Fozdar ${ }^{1}$ and Lisa Hartley ${ }^{2}$
}

The year 2011 marked the $60^{\text {th }}$ anniversary of the United Nations Refugee Convention. It is thus an appropriate time to review the situation of refugees in one of the few signatory countries that accepts UNHCR approved refugees, Australia. Australia takes around 14,000 refugees annually, from countries in the African, Middle Eastern and Asian regions. The Australian government funds a range of services to assist the settlement process, and these are recognized as among the best in the world. While these services provide assistance in the areas of employment, education and training, housing, language, health, social support, and cultural orientation, there is room for improvement to ensure social inclusion. This paper provides an overview of research undertaken with this population over the last fifteen years investigating some of the key barriers to social inclusion. It outlines a number of matters in need of policy improvement, and areas for further research.

Keywords: refugees, Australia, settlement, employment, integration, social inclusion

\footnotetext{
${ }^{1}$ Farida Fozdar is Professor of Anthropology and Sociology and Future Fellow (FT100100432) at the University of Western Australia.

${ }^{2}$ Lisa Hartley is a Lecturer at the Centre for Human Rights Education at Curtin University and Research Associate at the University of Western Australia. This research was partly funded by a grant from Lotterywest.
} 
Corresponding author:

Farida Fozdar

Professor, Anthropology and Sociology

The University of Western Australia

M255, 35 Stirling Hwy,

Crawley, 6009, Western Australia

farida.fozdar@uwa.edu.au

Word Count: 13, 892 


\section{Introduction}

The year 2011 marked the $60^{\text {th }}$ anniversary of the United Nations Refugee Convention, with no reduction in the numbers of refugees or refugee producing events worldwide. At the end of 2010, 43.7 million people were displaced by persecution and conflict, including 15.4 million refugees, 840,000 asylum seekers and 27.5 million internally displaced people (UNHCR, 2011). Almost 100,000 refugees were resettled by 21 resettlement countries, including the United States of America (71,362), Canada (12,098), and Australia $(8,516){ }^{3}$ The $60^{\text {th }}$ anniversary provides an opportunity reflection on the achievements and challenges of refugee resettlement.

Australia is ranked third in the world in terms of its resettlement commitment, and first in its per capita intake. For some decades it has offered settlement services based on general principles of equity and multiculturalism. However, there has been little systematic review of empirical research relating to settlement in Australia. The aim of the current paper is to review recent literature to better inform policy makers, practitioners and scholars, and to highlight areas of research in need of further investigation. The paper begins with an outline of resettlement objectives generally and details Australia's humanitarian intake and government-funded services. It then outlines research undertaken over the last 15 years focusing on a number of dimensions of settlement including economic (employment, housing, education and language); health (physical and mental); socio-cultural (support networks, racism, culture shock); and spatial (urban and regional settlement). It concludes with implications for policy and recommendations for further research.

\subsection{Resettlement, integration and social inclusion}

In Australia, successful settlement and integration are the key objectives of the Refugee and Humanitarian Program. The Australian Federal Government Department of Immigration and Citizenship (DIAC) uses a variety of measures to assess settlement outcomes. These include economic participation (labour force outcomes, occupational status, sources of income, level of income and housing); social participation and well-being (English proficiency, satisfaction with life and Australian citizenship); and physical and mental well-being. Information collection relating to these factors is not systematic however.

\footnotetext{
${ }^{3}$ UNHCR “Global Trends 2010.” United Nations High Commissioner for Refugees, 2011, available at: http://www.unhcr.org/4dfa11499.html (last visited 10 Sep. 2011)
} 
Since successful settlement is defined as integration it is worth considering what this term means. Goodwin-Gill argues: “a durable solution entails a process of integration into a society; it will be successful and lasting only if it allows the refugee to attain a degree of selfsufficiency, to participate in the social and economic life of the community and to retain what might be described...as a degree of personal identity and integrity". ${ }^{4}$ Valtonen also describes successful settlement in terms of integration, i.e. the ability to participate fully in economic, social, cultural and political activities. ${ }^{5}$ The UNHCR International Handbook to Guide Reception and Integration Handbook similarly provides a definition of settlement based on integration, which is seen as a mutual, dynamic, multifaceted and on-going process. ${ }^{6}$ It includes the restoration of refugees' security, control, and social and economic independence; promotion of family reunification, and connections with volunteers and professionals able to provide support; as well as promotion of cultural and religious integrity and restoration of attachments to community and culture, as well as the countering of racism, discrimination, and xenophobia.

The integration process is influenced by the institutional environment of the receiving society as well as personal capacities of the settling population. ${ }^{7}$ Ager and Strang suggest four domains of integration which act as both markers of integration and the means of achieving it: employment, housing, education and health. Social connections, in the form of bridges, bonds and links, which are facilitated by language, cultural knowledge, safety and stability, are another important dimension. Finally, they argue, the foundation of integration is built upon rights and citizenship. ${ }^{8}$

It is generally agreed that integration is a two-way process. For refugees, integration requires a preparedness to adapt to the lifestyle of the host society without having to lose one’s cultural identity. For the host society, it requires a willingness to be welcoming and responsive to refugees, and for public institutions to meet the needs of a diverse population. Importantly, unlike assimilation, it implies mutual adaptation, an openness to change to

\footnotetext{
${ }^{4}$ G. Goodwin-Gill "Refuge or Asylum: International Law and the Search for Solutions to the Refugee Problem.” In Refuge or Asylum: A Choice for Canada. Ed. H. Alderman, and C. Lanphier. Toronto: York Lane Press, 1990, 38.

${ }^{5}$ K. Valtonen. 2004 "From the Margins to the Mainstream: Conceptualizing Refugee Settlement Processes”. Journal of Refugee Studies 17(1), 70-96, 2004, 86.

${ }^{6}$ UNHCR 2002 Refugee resettlement: An international handbook to guide reception and integration, United Nations High Commissioner for Refugees, Geneva, 2002, 12.

${ }^{7}$ K. Valtonen, "From the Margins to the Mainstream", 88.

${ }^{8}$ A. Ager and A. Strang "Understanding Integration: A Conceptual Framework.” Journal of Refugee Studies 21(2), 2008, 166-191.
} 
improve the host society. ${ }^{9}$ This is somewhat fraught in the Australian context, given that the nation's identity was built on a mono-cultural White Australia Policy. While this policy was scrapped in the early 1970s and replaced with more open immigration and policies of multiculturalism, and despite Australia having the highest proportion of overseas born people in the Western world, it has remained relatively Eurocentric in outlook and identity. ${ }^{10}$ The last decade has seen a retreat from the multiculturalism of the late twentieth century, with xenophobic tendencies being inflamed by a conservative government. ${ }^{11}$ This has had implications for refugees settling during this period, some of which are evident in the research discussed below.

\subsection{Australia's humanitarian entrant intake}

Australia has a planned annual Humanitarian Program designed to respond to international refugee and humanitarian developments. This program has two components; the onshore protection program, which protects people already in Australia who are recognised as refugees under the 1951 Convention and the 1967 Protocol Relating to the Status of Refugees (known as asylum seekers until their cases are determined), and the offshore resettlement program, which offers resettlement through the UNHCR program. Table 1 indicates the intake over the last 15 years.

Table 1. Humanitarian Program Outcomes for the visas granted, 1995-96 - 2009-2010. ${ }^{12}$

\begin{tabular}{|c|c|c|c|}
\hline Onshore & Offshore & Total & $\begin{array}{c}\text { \% of Total } \\
\text { Immigration } \\
\text { Intake }\end{array}$ \\
\hline
\end{tabular}

\footnotetext{
${ }^{9}$ G. Delanty. Citizenship in a Global Age: Society, Culture and Politics. Buckingham and Philadelphia: Open University Press, 2000.

${ }^{10}$ G. Hage White Nation: Fantasies of White Supremacy in a Multicultural Society. Annadale NSW: Pluto Press, 1998.

${ }^{11}$ C. Joppke "The Retreat of Multiculturalism in the Liberal State: Theory and Policy.” The British Journal of Sociology 55(2), 2004, 237-257; J. Tate, J. “John Howard's 'Nation’ and Citizenship Test: Multiculturalism, Citizenship and Identity”. Australian Journal of Politics and History 55(1), 2009, 97-120; J. Jupp, From White Australia to Woomera, Melbourne: Cambridge University Press, 2007. Tilbury, F. "The Retreat From Multiculturalism: The Australian Experience.” Pluralism, Inclusion and Citizenship. Third Global Conference, Interdisciplinary.net, Salzburg, November 2007, available at: http://www.interdisciplinary.net/ati/diversity/pluralism/pl3/Tilbury\%20paper.pdf (last visited 1 Sept. 2011)

${ }^{12}$ Figures from Department of Immigration and Citizenship (DIAC) annual reports, 2005-06 to 2009-10, adapted and updated from G. Hugo A Significant Contribution: Economic, Social and Civic Contributions of First and Second Generation Humanitarian Entrants, 2011, available at: http://www.immi.gov.au/media/publications/research/_pdf/economic-social-civic-contributions-booklet2011.pdf (last visted 20 Sept. 2011).
} 


\begin{tabular}{lcccc}
\hline $\mathbf{1 9 9 5 - 9 6}$ & 1,200 & 15,050 & 16,250 & 13.8 \\
$\mathbf{1 9 9 6 - 9 7}$ & 2,250 & 9,650 & 11,900 & 11.3 \\
$\mathbf{1 9 9 7 - 9 8}$ & 1,590 & 10,470 & 12,060 & 12.0 \\
$\mathbf{1 9 9 8 - 9 9}$ & 1,830 & 9,530 & 11,360 & 10.8 \\
$\mathbf{1 9 9 9 - 0 0}$ & 2,460 & 7,500 & 9,960 & 8.8 \\
$\mathbf{2 0 0 0 - 0 1}$ & 5,740 & 7,990 & 13,730 & 9.9 \\
$\mathbf{2 0 0 1 - 0 2}$ & 3,900 & 8,450 & 12,350 & 9.6 \\
$\mathbf{2 0 0 2 - 0 3}$ & 870 & 11,660 & 12,530 & 9.1 \\
$\mathbf{2 0 0 3 - 0 4}$ & 2,049 & 11,802 & 13,851 & 9.3 \\
$\mathbf{2 0 0 4 - 0 5}$ & 1,082 & 12,096 & 13,178 & 8.4 \\
$\mathbf{2 0 0 5 - 0 6}$ & 1,386 & 12,758 & 14,144 & 7.8 \\
$\mathbf{2 0 0 6 - 0 7}$ & 1,831 & 11,186 & 13,017 & 6.8 \\
$\mathbf{2 0 0 7 - 0 8}$ & 2,215 & 10,799 & 13,014 & 6.3 \\
$\mathbf{2 0 0 8 - 0 9}$ & 2,497 & 11,010 & 13,507 & 6.2 \\
$\mathbf{2 0 0 9 - 1 0}$ & 4,523 & 9,301 & 13,770 & 8.2 \\
\hline
\end{tabular}

Interestingly, this table demonstrates that Australia's humanitarian intake decreased as a proportion of its immigration intake, until 2009-10, indicating a lowering of commitment to this segment of its migration program. However, it must be noted that a dramatic rise in migrant numbers occurred in the mid to late part of the first decade of the 2000s due to labour shortages caused by a booming economy, while the number of humanitarian visas granted did not, resulting in this proportional decrease.

Historically refugees to Australia came predominantly from Europe as post WWII Displaced Persons, and then from Lebanon or Indo-China (particularly Vietnam) in the 1970s following civil disturbances, with smaller numbers from Latin America in the 1980s. In the last two decades refugees hailed mainly from the Middle East and North Africa, the former Yugoslavia, the Horn of Africa and West Africa and Afghanistan. Most recently Sri Lanka, Myanmar and Bhutan are also key source countries.

\subsection{Australia’s services for humanitarian entrants}

In Australia, services to refugees and asylum seekers are provided by government and nongovernment organizations. More or less formal groups of volunteers also assist. Most government-funded services are contracted out to non-governmental organizations (NGOs), making coordination and long-term development of institutional capacity difficult. Initial settlement assistance is reasonably extensive. One of the major services is the Adult Migrant English Program (AMEP) which provides 510 hours of free English language tuition. Refugees can also access dedicated settlement services for the first six to twelve months of settlement (currently referred to as the Humanitarian Settlement Strategy (HSS)). This 
program provides reception and assistance on arrival (meeting at the airport, taking to accommodation, assisting with accommodation costs, orientation, and emergency medical and clothing assistance); information and referrals (to government agencies that provide income support, health care, English language classes and employment services), housing services (help finding suitable housing, assistance with leasing and connection to services like electricity, gas, and the telephone, provision of household goods such as a refrigerator, washing machine, TV and beds, information about household care and cleanliness), and a package of food and hygiene products for the first few days. It also provides short-term torture and trauma counselling to those requiring it. Those who come as sponsored humanitarian entrants are expected to receive a similar level of assistance from their proposers, which proves difficult as proposers are often also refugees struggling to settle.

In terms of cultural orientation, a five day pre-arrival course is available, but after arrival mutual cultural understanding program provision has been patchy. The most recent revision of Australia's settlement services in 2011 includes an onshore cultural orientation program. It remains to be seen how effective this is in preparing humanitarian entrants for the challenges of living in the new host country.

Six to twelve months after arrival, humanitarian entrants are exited from HSS. After this time, government funded services (known as the Settlement Grants Program (SGP)) are provided according to need. These programs tend to have a specific focus, such as job search skills development, although service providers are increasingly adapting them to provide case-based support. The funding covers initiatives that support immigration assistance, housing, and ethno-specific activities for new communities, focused around the themes of orientation to Australia, developing communities, and integration. In the 2010-2011 funding round, many grants were targeted at young people and African communities. ${ }^{13}$

\subsection{An overview of dimensions of settlement in Australia}

While not all humanitarian entrants have high and complex needs and many maintain high levels of personal resilience, a sense of community and a strong work ethic, ${ }^{14}$ research

\footnotetext{
${ }^{13}$ Refugee Council of Australia (RCOA) The Settlement Grants Program 2007-2011: An Overview of Funding Trends. 2011, available at: http://www.refugeecouncil.org.au/resources/reports/2007-11_SGP.pdf (last visited Sept. 2011).

${ }^{14}$ E. Pittaway, C. Muli, and S. Shteir “'I Have a Voice - Hear Me!’: Findings of an Australian Study Examining the Resettlement and Integration Experience of Refugees and Migrants From the Horn of Africa in Australia.” Refuge 26(2), 2009, 133-146; I, Correa-Velez, S. Gifford, and A. Barnett "Longing to Belong: Social Inclusion and Wellbeing Among Youth With Refugee Backgrounds in the First Three Years in Melbourne, Australia.”
} 
suggests that refugees do not settle as easily as other migrants in Australia. In moving to new environments, humanitarian entrants experience a range of issues related to language; education; differences of values; unemployment; family issues including family violence, inter-generational conflict, changing gender roles and child rearing practices; expectations; knowledge of and access to services; housing; and health and mental health issues. ${ }^{15}$ Many of these issues are mediated by poverty - most refugees arriving in Australia are poor in terms of income and assets and therefore face the same day-to-day challenges as others living in poverty, overlaid with pre-migration experiences, additional expenses, and policies which exclude some from income support. ${ }^{16}$ In addition, refugees must overcome the racism that still permeates Australian society. ${ }^{17}$ They also face significant challenges in terms of access

Social Science and Medicine 71, 2010, 1399-1408; RCOA Economic, Civic and Social Contributions of Refugees and Humanitarian Entrants: A Literature Review, 2010, available at: http://www.refugeecouncil.org.au/resources/reports.html (last visited 14 Sept 2011).

${ }^{15}$ See P. Waxman "Service Provision and the Needs of Newly Arrived Refugees in Sydney Australia: A Descriptive Analysis.” International Migration Review 32(3), 1998, 761-767; S. Richardson, L. Miller-Lewis, P. Ngo, and D. Ilsley The Settlement Experiences of New Migrants. A Comparison of Wave One of LSIA 1 and LSIA 2. (Report Prepared for the Department of Immigration and Multicultural and Indigenous Affairs). 2001, Canberra: Commonwealth of Australia; S, Richardson, Stack, L. Lester, J. Healy, D. Ilsley, and J. Horrocks The Changing Labour Force Experience of New Migrants: Inter-Wave Comparisons for Cohort 1 and 2 of the LSIA. (Report to the Department of Immigration and Multicultural and Indigenous Affairs). Canberra: Commonwealth of Australia, 2004; V. Colic-Peisker and F. Tilbury "Integration into the Australian Labour Market: The Experience of Three ‘Visibly Different’ Groups of Recently Arrived Refugees.” International Migration 45(1), 2007, 59-85; F. Tilbury “'I Feel I Am a Bird Without Wings’: Discourses of Sadness and Loss Among East Africans in Western Australia.” Identities: Global Studies in Culture and Power 14(4), 2007, 433-458; F. Fozdar and S. Torezani "Discrimination and Wellbeing: Perceptions of Refugees in Western Australia." International Migration Review 42(1), 2008, 30-63; RCOA Australia's Refugee and Humanitarian Program: Community Views on Current Challenges and Future Directions. Sydney, 2008; Refugee Council of Australia; RCOA Australia's Refugee and Humanitarian Program: Community Views on Current Challenges and Future Directions. Sydney: Refugee Council of Australia, 2009; RCOA “Economic, Civic and Social Contributions”, 2010; S. Dhanji. "Welcome or Unwelcome?: Integration Issues and the Resettlement of Former Refugees From the Horn of Africa and Sudan in Metropolitan Melbourne.” Australasian Review of African Studies 30(2), 2009, 152-178; C. Fisher. The Exploration of the Nature and Understanding of Family Violence Within Sudanese, Somalian, Ethiopian, Liberian and Sierra Leonean Communities and its Impact on Individuals, Family Relations, the Community and Settlement. Sydney: Association for Services to Torture and Trauma Survivors, 2009; F. Fozdar “"The golden country”: Ex-Yugoslav and East African Refugee Experiences of Settlement and 'Depression'.” Journal of Ethnic and Racial Studies 35(8), 2009, 1335-1352; E. Pittaway et. al. “'I Have a Voice - Hear Me!'”, 133-146; C. Nunn. "Spaces to Speak: Challenging Representations of SudaneseAustralians.” Journal of Intercultural Studies 31(2), 2010, 183 -198; G. Hugo “A Significant Contribution” ${ }^{16}$ J. Taylor. "Refugees and Social Exclusion: What the Literature Says.” Migration Action 26(2), 2004, 16 -31.

${ }^{17}$ A. Markus. Mapping Social Cohesion, Caulfield East: Monash University, 2012, available at www.arts.monash.edu.au/mapping-population (last visited 14 Nov 2012). L. Majka. “African Refugee Settlement Assistance in Melbourne.” Migration World 25(5), 1997, 26-29; N. Klocker, and K. Dunn “Who’s Driving the Asylum Debate? Newspaper and Government Representations of Asylum Seekers.” Media International Australia, 109, 2003, 71-92; A. Pedersen, J. Attwell, and D. Heveli "Prediction of Negative Attitudes Toward Australian Asylum Seekers: False Beliefs, Nationalism and Self-Esteem.” Australian Journal of Psychology 57, 2005, 148-160; A, Pedersen, S. Clarke, P. Dudgeon, and B. Griffiths "Attitudes Toward Indigenous-Australians and Asylum-Seekers: The Role of False Beliefs and Other Social-Psychological Variables." Australian Psychologist 40(3), 2005,170-178; A. Pedersen, S. Watt, and S. Hansen "The Role of False Beliefs in the Community's and the Federal Government's Attitudes Toward Australian Asylum Seekers.” Australian Journal of Social Issues 41(1), 2006, 105-124; V. Colic-Peisker and F. Tilbury Eds.” In 
to services including lack of coordination of services (difficult, in a context of contracted services) and for providers to understand the 'real' as opposed to perceived settlement experiences. $^{18}$

Two comprehensive reports providing overviews of the settlement of refugees in Australia have recently been published. The Department of Immigration and Citizenship commissioned a study known as the Settlement Outcomes of New Arrivals (SONA) report. ${ }^{19}$ This research compared the first five years of settlement of those coming through the Humanitarian Program, with that of those migrating through other streams, using a selfcompletion paper survey. It explored the relationship between settlement, defined as level of comfort living in Australia, and education, interaction with government, employment, income, accommodation, English proficiency, regional location and social connection. It found that, of the indicators, those that best predicted humanitarian entrants' level of comfort were: happiness about themselves; confidence about making choices; being treated well by the local community; and ease of finding a place to live in Australia. Results are discussed as part of this review. It provided a mixed picture of the settlement experiences of refugees compared with other migrants, demonstrating some disadvantage on a number of parameters.

The second is a report by Graeme Hugo and his team, ${ }^{20}$ who undertook a comprehensive study of the economic, social and civic contributions of humanitarian entrants and their offspring using a number of existing data sources such as the Census, the humanitarian settlement data base, the Longitudinal Survey of Immigrants in Australia (LSIA) and the Australian Bureau of Statistics Labour Force surveys, as well as the SONA data described above. They also interviewed or conducted surveys or focus groups with key stakeholders, service providers, researchers, and humanitarian entrants themselves. Hugo found that in the long term, humanitarian entrants and their children demonstrate considerable achievement and contribution to Australian society. This is due to a number of factors including a low rate of settler loss (in the form of return migration), relatively high

Settling in Australia: The Social Inclusion of Refugees. Perth: Centre for Social and Community Research, Murdoch University, 2007; F, Tilbury and V. Colic-Peisker "Deflecting Responsibility in Employer Talk about Race Discrimination.” Discourse and Society, 17(5), 2006, 651-676.

${ }^{18}$ P. Waxman "Service Provision”, 761-767; R. Perrin and K. Dunn "Tracking the Settlement of North African Immigrants: Speculations on the Social and Cultural Impacts of a Newly Arrived Immigrant Group.” The Australian Geographer 38(2), 2007, 253-273; S. Torezani, V. Colic-Peisker, and F. Fozdar "Looking for a 'Missing Link': Formal Employment Services and Social Networks in Refugees' Job Search.” Journal of Intercultural Studies 29(2), 2008, 135-152.

${ }^{19}$ Australian Survey Research Group (ASRG) Settlement Outcomes of New Arrivals - Report of Findings: Study for Department of Immigration and Citizenship. Sydney: Australian Survey Research Group, 2011.

${ }^{20}$ G. Hugo “A Significant Contribution”. 
fertility rates and high proportions of second generation working for the majority of their lives in Australia. As well as contributing to their countries of origin economically through remittances, humanitarian settlers make significant contributions within Australia through volunteering in both the wider community and within their own community groups.

This good news story is often lost in research which tends to focus on the needs of refugees rather than their contributions. The following review of the literature must be read in this light, therefore.

\section{Methodology}

This review focusses on Australian material published between 1994 and August 2011. Literature was obtained through an extensive search of library data bases and Internet searches. Keywords used included refugee, humanitarian, settlement, and Australia (Boolean techniques were used). The researchers also used their own resources and personal contacts to obtain additional material. As well as academic materials, government and peak body reports have been included.

One limitation identified is the relative dearth of literature differentiating refugees from other migrants. While refugees face many challenges in common with other migrants, they also have needs peculiar to their situation. It is therefore unfortunate that the available literature often concerns policies, services and integration issues for migrants generally. Where this is the case, it can be difficult to assess or accurately convey how refugees fit into the broader picture. Another confounding factor is that there are different categories of refugee with different levels of access to services. Further, the terms refugee, asylum seeker and humanitarian entrant tend to be used interchangeably. In order to avoid eliding these groups, we have excluded from this study research about onshore applicants for asylum whose status has not yet been determined, as their experiences and policies relating to them are significantly different from those whose status as refugees has been determined. A further problem is the inability to generalise the findings of the many qualitative studies which tend to be small scale and ethnic-community specific. Finally, it must be noted that while the Australian government has recently funded a large longitudinal quantitative study of settlement outcomes for humanitarian entrants, to date there has been little quantitative research about the prevalence of some of the issues identified.

\section{Economic dimensions of settlement}

\subsection{Employment}


Employment is pivotal in successful settlement. Paid work is essential not only for refugees to be able to support family members in the host country and overseas, but it is also vital in regaining a positive sense of identity and control over their lives. ${ }^{21}$ Refugees prioritise employment for these reasons. ${ }^{22}$ Indeed research shows a strong desire among refugees to be in gainful employment rather than on welfare. ${ }^{23}$ Despite this, refugees experience difficulty integrating into the labour market for various reasons.

Refugees in Australia have higher unemployment rates and lower earning and occupational attainment than other immigrants. ${ }^{24}$ They are vulnerable to long term unemployment and are less likely to secure 'good' jobs. ${ }^{25}$ Some 18 months after arrival 43 per cent of humanitarian entrants remain unemployed compared with 7 per cent for those who enter Australia under other visa categories. ${ }^{26}$ However, this does not remain the case over longer periods - refugee second generation have higher levels of labour market participation than the general population. ${ }^{27}$

There are many reasons for these poor employment outcomes. Hugo ${ }^{28}$ notes that the data is influenced by recency of arrival and the relative youth of the population. The most recently arrived groups have the lowest levels of labour market participation. In securing employment, English proficiency is crucial $^{29}$ however other factors such as failure to have overseas qualifications recognised, lack of work experience and referees, and structural and personal discrimination negatively affect outcomes. ${ }^{30}$ The significance of qualification

\footnotetext{
${ }^{21}$ C. Iredale "Skills Recognition and Refugees: Migrants Without Options.” Australian Journal of Social Issues 29(3), 1994, 241-264. C Iredale, C. Mitchell, R. Pe-Pau, and E. Pittaway Ambivalent Welcome: The Settlement Experiences of Humanitarian Entrant Families in Australia. Canberra: Department of Immigration and Ethnic Affairs, 2006; V. Colic-Peisker, "Bosnian Refugees in Australia: Identity, Community and Labour Market Integration’, New Issues in Refugee Research. UNHCR Working Paper No. 97. 2003, available at: http://www.unhcr.org/3fb4f8a64.pdf (last visited 10 Aug. 2011).

${ }^{22}$ Urbis Keys Young Evaluation of the Integrated Humanitarian Settlement Strategy. Report prepared for the Department of Immigration and Multicultural and Indigenous Affairs, 2003, available at: http://www.immi.gov.au/media/publications/pdf/evaluation_report.pdf (last visited 17 Aug. 2011)

${ }^{23}$ F. Fozdar "The Golden Country", 30-63.

${ }^{24}$ L. Williams and T. Batrouney "Immigrants and Poverty.” In Australian Poverty: Then and Now. Ed. R. Fincher and J. Nieuwenhuysen. Melbourne: Melbourne University Press, 1998, 258-275; V. Colic-Peisker and F. Fozdar, "Integration into Australian Labour Market”, 59-85. G. Hugo “A Significant Contribution”.

${ }^{25}$ P. Junankarand and S. Mahuteau "Do Migrants get Good Jobs?: New Migrant Settlement in Australia." Economic Record 8, 2005, S34-S46

${ }^{26}$ G. Hugo “A Significant Contribution”, 110.

${ }^{27}$ Ibid

${ }^{28}$ Ibid

${ }^{29}$ P. Waxman "The Economic Adjustment of Recently Arrived Bosnian, Afghan and Iraqi Refugees in Sydney, Australia.” International Migration Review 35(2), 2001, 472-505; J. Taylor, "Refugees and Social Exclusion” 16-31.

${ }^{30}$ V. Colic-Peisker and F. Tilbury “Integration into the Labour Market”, 59-85.
} 
recognition issues was highlighted in a Joint Standing Committees report Negotiating the Maze. $^{31}$

Evaluations of employment assistance service provision indicate the need for improved targeted assistance including financial incentives for service providers to focus on this disadvantaged group. ${ }^{32}$ While some programs provide dedicated pre-employment and employment services, it is unclear how successful these have been. It has also been recognised that there is no coordinated youth focus in early resettlement programs resulting in poor outcomes. ${ }^{33}$

The perception by refugees and stakeholders of the reasons for employment difficulties has been the subject of several research projects. Tilbury and Colic-Peisker conducted research in Perth, Western Australia, among three groups of refugees - those from the former Yugoslavia, from the Middle East and from Africa. ${ }^{34}$ Using a sample of relatively skilled/educated refugees, they found the main barriers to satisfactory employment identified by respondents were a lack of Australian work experience (62 per cent), lack of Australian referees (41 per cent), and recognition of oversees qualifications (31 per cent). Institutional and personal racism also affect outcomes. ${ }^{35}$ Stakeholders in Hugo's study noted that premigration issues such as exposure to violence, limited education, lack of documentation, lack of knowledge about the Australian labour market and misinformation about opportunities exacerbate issues derived from the Australian context such as health and mental health issues, literacy deficiencies, lack of access to skills recognition processes (including cost issues), limited social networks, inadequate employment assistance service provision (including lack of trained personnel, and financial incentives structures that disadvantage the most needy jobseekers), and unrealistic expectations, together with employer discrimination, affect outcomes. $^{36}$

\footnotetext{
${ }^{31}$ Commonwealth of Australia Negotiating the Maze: Review of Arrangements for Overseas Skills Recognition, Upgrading and Licensing, 2006, available at:

http://www.aph.gov.au/house/committee/mig/recognition/report.htm (last visited 13 Sept. 2011)

32 S. Torenzani et. al.“Looking for a 'Missing Link'”, 135-152; Refugee Council of Australia What Works:

Employment strategies for refugee and humanitarian entrants, 2012, available at http://www.refugeecouncil.org.au/r/rpt.php (last visited 14 Nov. 2012).

${ }^{33}$ CMYI Refugee Young People and Resettlement. Melbourne: Centre for Multicultural Youth Issues, 2006 ; K. O’Sullivan and L. Olliff Settling In: Exploring Good Settlement for Refugee Young People in Australia. Melbourne: Centre for Multicultural Youth Issues, 2006.

${ }^{34}$ V. Colic-Peisker and F. Fozdar "Integration into the Australian Labour Market”, 59-85.

${ }^{35}$ V. Colic-Peisker and F. Fozdar "Employment Niches for Recent Refugees: Segmented Labour Market of the

21st Century Australia.” Journal of Refugee Studies 19(2), 2006, 203-229.

${ }^{36}$ G. Hugo “A Significant Contribution”, 164
} 
Hugo's study also offers empirical evidence that levels of English language proficiency and educational background are directly related to employment outcomes for humanitarian entrants. Like the Australian population generally, the more education one has, the more likely one is to be employed. However even highly educated refugees often have difficulty finding work. One third of employed humanitarian settlers work as labourers three times the rate of other recent settlers. ${ }^{37}$ Despite relatively high levels of education, many are employed in manual occupations, with only 10 per cent being managers or professionals, compared to almost 40 per cent of all migrants, providing evidence of 'occupational skidding'. Hugo reports income levels are correspondingly relatively low. His respondents suggested that the idea of 'sacrifice' is common among first generation humanitarian entrants, who hope their hard work at often dirty, dangerous and low paid jobs will reap benefits for their children.

There is also evidence that some groups of refugees funnel into low paid, low skilled, low status, niche labour markets such as security, meat processing, child/aged care, and taxidriving. This is the result of factors identified above, plus the limitations of refugees' social networks resulting in a 'chain employment' effect within certain industries, producing a segmented secondary labour market. ${ }^{38}$

Perhaps partly as a result of breaking into the mainstream labour market, very high relative levels of entrepreneurialism are found among humanitarian entrants. It has been hypothesised that this may be related to a propensity for risk taking, ${ }^{39}$ but it is as likely to be the result of lack of opportunities/success in the general employment market.

Although the available research offers significant insights into the employment outcomes of humanitarian entrants settling in Australia, there is a clear need for longitudinal research into employment outcomes for refugees, as highlighted by Hugo. ${ }^{40}$

\subsection{Education and training}

Education and training is another of the cornerstones of successful settlement, both in terms of English language education and in regard to training to maximise employment opportunities. However, one-quarter of refugees do not take up English language tuition for various reasons including the prioritising of employment but also because of logistical

\footnotetext{
${ }^{37}$ Ibid, 145.

${ }^{38}$ V. Colic-Peisker and F. Fozdar "Employment Niches for Recent Refugees”.

${ }^{39}$ G. Hugo “A Significant Contribution”.

${ }^{40}$ Ibid.
} 
difficulties, particularly for mothers of young children. As well as issues of access, concerns have been raised regarding the adequacy of the Adult Migrant English Program, in particular for those students who are illiterate in their first language, for professionals, and in terms of its lack of focus on English for the workplace. ${ }^{41}$ The AMEP undergoes constant processes of review with the goal of improving the program and has been working to address this issue. At a broader level, six to twelve months of language training may be grossly inadequate for those who have not experienced formal learning before and are not literate in their first language. ${ }^{42}$

In regard to access to and experiences of post-secondary school education indications from Walker and colleagues ${ }^{43}$ and $\mathrm{OMI}^{44}$ concerning apprenticeships and traineeships suggest there are numerous barriers including lack of knowledge of opportunities, language, income levels, and employer reticence, together with a desire to 'aim high' in terms of tertiary education options. This is despite education and training being known to be important goals among refugee youth ${ }^{45}$ and re-training being an important pathway for re-entry into the workforce for adult refugees. Many humanitarian entrants and their offspring have sought to extend their skills through tertiary education, both as a means of improving their life-chances and assisting their communities, but also as a prestige factor. ${ }^{46}$ Research also indicates that the relationship between culture, community and learning significantly affects educational outcomes at the tertiary level. ${ }^{47}$ Refugee engagement with learning is mediated through

\footnotetext{
${ }^{41}$ RCOA Australia's Refugee and Humanitarian Program: Community Views on Current Challenges and Future Directions. Sydney: Refugee Council of Australia, 2007; Moore, H, H. Nicholas, and J. Deblaquiere 'Opening the Door': Provision for Refugee Youth With Minimal/No Schooling in the Adult Migrant English Program. Project 2.1: 'Modes of Delivery for SPP Youth', AMEP Research Centre, Commonwealth of Australia, 2008, available at: http://www.ameprc.mq.edu.au/docs/research_reports/research_report_series/Opening_the_door.pdf (last visited 3 Sept. 2011)

${ }^{42}$ L. Olliff and J. Couch "Pathways and Pitfalls: The Journey of Refugee Young People in and Around the Education System in Greater Dandenong, Victoria.” Youth Studies Australia 24(3), 2005, 42-46.

${ }^{43}$ I. Walker, F. Tilbury, S. Volet, C. Tungaraza, and B. Hastie Pathways to Apprenticeships and Traineeships for People From Culturally and Linguistically Diverse Backgrounds. Perth: Prepared on behalf of the Western Australian Department of Education and Training, 2005.

${ }^{44}$ OMI The Journey to Best Practice: Achieving Apprenticeships and Traineeships for People From Culturally and Linguistically Diverse Backgrounds. Perth: Office of Multicultural Interests, 2009.

${ }^{45}$ Gifford, S., I. Correa-Velez, and R. Sampson Good Starts for Recently Arrived Youth With Refugee Backgrounds: Promoting Wellbeing in the First Three Years of Settlement in Melbourne, Australia. Melbourne: La Trobe Refugee Research Centre, 2009, available at: http://www.latrobe.edu.au/larrc/documentslarrc/reports/report-good-starts.pdf (last visited 18 Sept. 2011).

${ }^{46}$ A. Joyce. J. Earnest, G. de Mori, and G. Silvagni "The Experiences of Students From Refugee Backgrounds at Universities in Australia: Reflections on the Social, Emotional and Practical Challenges.” Journal of Refugee Studies 23(1), 2010, 82-97; M. Turner and F. Fozdar "Negotiating 'Community' in Educational Settings: Adult South Sudanese Students in Australia.” Journal of Intercultural Studies 31(4), 2010, 363-382.

${ }^{47}$ M. Turner and F. Fozdar 2010 “Negotiating 'Community'.
} 
different levels of community: an immediate ethnic group, a broader national refugee community, and the wider Australian community, the needs of which are often in tension, affecting achievement. Similar issues were identified in Harris and Marlowe's study of African background students, who were found to face challenges adapting to new educational contexts, dealing with community expectations, and with difficult home environments for study. They had difficulty accessing academic support, study materials, and with studying in another language. Students tended to rely on themselves or their peers of similar backgrounds for support. ${ }^{48}$ Australian schools and universities need to orient to these issues to ensure positive outcomes.

There are particular issues for young people in terms of education and training. For school-aged children and adolescents, Intensive English Centres (IECs) within mainstream schools provide students with intensive language training to ensure they are school ready, but little research exists regarding access to these services or their efficacy. ${ }^{49}$ For Australia's newest refugee cohort, those from Africa, low levels of literacy, significant cultural difference, and possible trauma related to displacement experiences leave refugees at a disadvantage in the school system. ${ }^{50}$ A useful resource on education issues for young people is the RCOA's annotated bibliography which details projects designed to identify or address refugee young people's post-compulsory education and training needs. ${ }^{51}$ Issues include disrupted education; ${ }^{52}$ difficulties navigating different education systems; ${ }^{53}$ negotiating settlement, education and family responsibilities; ${ }^{54}$ low levels of literacy and challenges for students from oral-based cultures; ${ }^{55}$ assessing and addressing learning disabilities; ${ }^{56}$

\footnotetext{
${ }^{48}$ V. Harris, V. and JM.. Marlowe "Hard Yards, High Hopes: The Educational Challenges of African Refugee Students”, The International Journal of Teaching and Learning in Higher Education, 23 (2), 2011,186-196.

${ }^{49}$ Cassidy, E., and G. Gow "Making Up for Lost Time: The Experiences of Southern Sudanese Young Refugees in High Schools.” Youth Studies Australia 24(3), 2005, 51-55.

${ }^{50}$ See J. Brown, J. Miller, and J. Mitchell "Interrupted Schooling and the Acquisition of Literacy: Experiences of Sudanese Refugees in Victorian Secondary Schools.” Australian Journal of Language and Literacy 29(2), 2006, 150-162; P. Westoby "Developing a Community-Development Approach through Engaging Resettling Southern Sudanese Refugees in Australia.” Community Development Journal 43(4), 2008, 483-495; J. Matthews "Schooling and Settlement: Refugee Education in Australia." International Studies in Sociology of Education 18(1), 2008, 31-45.

${ }^{51}$ RCOA Finding the Right Time and Place: Exploring Post-Compulsory Education and Training Pathways for Young People From Refugee Backgrounds in NSW, 2009, available at: http://www.refugeecouncil.org.au/resources/reports/2010_Education.pdf (last visited 17 Sept. 2011)

52 J. Brown et. al.“Interrupted Schooling”; H. Moore et. al.“Opening the Door”.

${ }^{53}$ CMYI "Refugee Young People"

${ }^{54}$ J. Brown et. al.“Interrupted Schooling”; H. Moore et. al.“Opening the Door”.

${ }^{55}$ H. Moore et. al.“Opening the Door”; U. Burgoyne and O. Hull Teaching Learners From Highly Oral Cultural Backgrounds: Good Practice Guide. Department of Education, Science and Training, 2007, available at: http://www.ncver.edu.au/publications/1804html (last visited 30 Sept. 2011)
} 
negotiating the difference between expectations and reality; ${ }^{57}$ and the transition from IECs to mainstream education. ${ }^{58}$ A career guidance package for refugee young people was developed in Western Australia which attempts to redress the lack of knowledge around career options. $^{59}$

While some programs have been designed to assist refugee parents and teachers to meet the needs of youth from refugee backgrounds, ${ }^{60}$ there is a dearth of systematic information about how best to facilitate education at this level. Additional challenges arise when their abilities and interactions affect school performance. ${ }^{61}$ The supportive role young people take at home and issues related to disrupted education or lack of education in their countries of origin make schooling in Australia challenging. ${ }^{62}$ The difficulties of minimal educational background and the pressures of supporting family in Australia and elsewhere make schooling very difficult, decreasing the likelihood of a successful transition to tertiary study which is a goal of many. In terms of training that leads to employment, action research in the state of Victoria indicates mentoring, training and work placements are vital for successful employment outcomes. ${ }^{63}$

\subsection{Language}

Language is related to most settlement factors, particularly education, employment and social networks. It is vital for social inclusion. It is included here in the section on material and

\footnotetext{
${ }^{56}$ H. Moore et. al.“Opening the Door”; N. Fraine and R. McDade "Reducing Bias in Psychometric Assessment of Culturally and Linguistically Diverse Students From Refugee Backgrounds in Australian Schools: A Process Approach.” Australian Psychologist 44, 2009, 16-26; I. Kaplan “The Effects of Trauma and the Refugee Experience on Psychological Assessment Processes and Interpretation.” Australian Psychologist 44, 2009, 6-15; Y. Stolk "Editorial. Approaches to the Influence of Culture and Language on Cognitive Assessment Instrument: The Australian Context.” Australian Psychologist, 44, 2009,1-5.

${ }^{57}$ J. Brown et. al.“Interrupted Schooling”; H. Moore et. al.“Opening the Door”.

${ }^{58}$ E. Cassidy and G. Gow "Making Up for Lost Time: The Experiences of Southern Sudanese Young Refugees in High Schools.” Youth Studies Australia 24(3), 2005, 51-55.

${ }^{59}$ D. Gallegos and Tilbury, F Career Development Program for Refugee and Migrant Youth, Centre for Social and Community Research, Murdoch University, Perth, 2006, available at:

http://www.cscr.murdoch.edu.au/research.html\#career_guidance (last visited 18 Sept. 2011)

${ }^{60}$ E.g., L. Kyle, F. MacDonald, J. Doughney, and J. Pyke Refugees in the Labour Market: Looking for CostEffective Models of Assistance. The Ecumenical Migration Centre Brotherhood of St Laurence, 2004, available at: http://www.bsl.org.au/pdfs/refugees_in_labour_market.pdf (last visited 29 Aug. 2011)

${ }^{61}$ C. Driver and R. Beltran "Impact of Refugee Trauma on Children's Occupational Role as School Students.” Australian Occupational Therapy Journal 45(1), 1998, 23-38.

${ }^{62}$ M. Brough, D. Gorman, E. Ramirez, and P. Westoby "Young Refugees Talk about Well-Being: A Qualitative Analysis of Refugee Youth Mental Health From Three States.” Australian Journal of Social Issues 38(2), 2003, 193-209; E. Cassidy and G. Gow "Making Up for Lost Time” 51-55.

${ }^{63}$ Mestan, K. Given the Chance: An Evaluation of an Employment and Education Pathways Program for Refugees. Melbourne: Brotherhood of St Laurence Research and Policy Centre, 2008, available at: http://www.bsl.org.au/pdfs/Mestan_GivenTheChance_evaluation.pdf (last viewed 18 Sept. 2011)
} 
economic issues as it is this sphere where it has its most obvious impact. This is not to deny its significance in terms of social aspects of settlement and integration.

Most refugees to Australia come from backgrounds where English is not their first language. However, the levels of English language proficiency vary widely, making service provision difficult. Hugo found that the proportion of migrants who arrived since 2001 who could not speak English well or at all was significantly higher for humanitarian arrivals (36.5 per cent) than for other visa groups, especially skilled migrants. ${ }^{64}$ English proficiency has been consistently found to be a crucial factor affecting settlement for migrants in general and employment specifically. ${ }^{65}$ For example, in 2006, 74 per cent of humanitarian migrants who did not speak English well or at all were not in the labour force. ${ }^{66}$

As noted, while the AMEP is constantly being improved, criticisms remain about its adequacy for those illiterate in their first language, and its suitability for the development of both workplace and conversational English. ${ }^{67}$ For high level professionals among the refugee intake, the program has also been identified as inadequate. ${ }^{68}$

\subsection{Housing}

Housing and sense of place are vital for the development of a sense of belonging, particularly for refugees, who have been denied access to a stable home of origin. ${ }^{69}$ Appropriate housing provides refugees with a place to begin to re-make 'home' ${ }^{70}$ While housing is often listed as one of the crucial elements in successful settlement, there remains little research on the experiences of refugees in accessing stable housing or the factors influencing movement. ${ }^{71}$

\footnotetext{
${ }^{64}$ G. Hugo “A significant contribution”, 127.

${ }^{65}$ M. Wooden “The Labour-Market Experience of Immigrants.” In Australian Immigration: A Survey of the Issues. Ed. M. Wooden, R. Holton, G. Hugo, and J. Sloan. Canberra: Australian Government Publishing Service, 2004, 218-279; M. Wooden “The Economic Impact of Immigration.” In Australian Immigration: A Survey of the Issues. Ed. M. Wooden, R. Holton, G. Hugo, and J. Sloan. Canberra: Australian Government Publishing Service. 2004,111-157.

${ }^{66}$ G. Hugo “A Significant Contribution”, 128.

${ }^{67}$ RCOA “Australia’s Refugee and Humanitarian Program”, 2007; H. Moore et. al.“Open the Door”

${ }^{68}$ F. Tilbury, S. Clark, R. Slee, and I. O’Ferrall Listening to Diverse Voices Multicultural Mental Health Promotion Research Project - Eritrean, Ethiopian, Somali and Sudanese Communities in Western Australia. Perth: East Metropolitan Population Health Unit and Murdoch University, 2005, available at: http://www.healthyfuture.health.wa.gov.au/ and http://www.cscr.murdoch.edu.au/ (last visited 28 Sept. 2011)

${ }^{69}$ R. Sampson and S. Gifford "Place-Making, Settlement and Well-Being: The Therapeutic Landscapes of Recently Arrived Youth With Refugee Backgrounds.” Health \& Place 16, 2010, 116-131.

${ }^{70}$ F. Tilbury et. al."Listening to Diverse Voices”; A. Dawson and N. Rapport Migrants of Identity: Perceptions of Home in a World of Movement. New York and Oxford: Berg, 1998.

${ }^{71}$ Association for Services to Torture and Trauma Survivors (ASeTTS) Hidden Homelessness: The Impact of Homelessness on Newly Arrived Youth. Perth: Association for Services to Torture and Trauma Survivors, 2008; M. Burgermeister, B. Kitching, and N. Iscel Housing Crisis Committee for Culturally and Linguistically Diverse Communities. Perth: Shelter WA and Tenants Advice Service (WA), 2008, available at:
} 
The Australian Housing and Urban Research Institute has recently funded a three-year study which should begin to address this gap. The research that is available identifies refugees as a group vulnerable to experiencing housing crisis and/or homelessness. ${ }^{72}$ Although humanitarian entrants face the same problems as many other low-income households, they often lack knowledge of the language, customs, and strategies relevant to accessing housing. $^{73}$

Research has found that three quarters of refugees rent privately or use community housing and move, on average, three times in their first year. ${ }^{74}$ It is unclear whether this level of housing instability is seen as a problem by refugees, or whether it is their choice. The 2006 Census data shows that humanitarian entrants are far less likely to be purchasing their own homes 5 years after arrival than other visa holders. ${ }^{75}$ This may indicate the level of difficulty they face in the early years in establishing language competency, education and employment, resulting in a delay in their access to secure and stable housing. In a study based on data from the Longitudinal Survey of Immigrants to Australia, Forrest and colleagues found that most humanitarian entrants initially live with family or friends, before moving into longer term private rental accommodation, although the experience differs by community. ${ }^{76}$

Research exploring the housing experiences of refugees in Australia suggests a number of barriers. ${ }^{77}$ These include: a lack of affordable housing in the private rental market; the tightening of eligibility for public housing; long waiting lists for public housing; a decrease in public housing stock; a lack of knowledge regarding tenancy issues; the need to be employed; lack of capital; difficult application processes including lack of rental

http://www.shelterwa.org.au/publications/papers_reports/2008/Gaps_in_Housing_and_Support_for_Humanitari an_Communities.pdf (last visited 8 Oct. 2011); E. Kelly A New Country - But No Place to Call Home: The Experiences of Refugees and Asylum Seekers in Housing Crisis and Strategies for Improved Housing Outcomes. Melbourne: Hanover Welfare Services, 2004.

${ }^{72}$ A. Beer and P. Foley Housing Need and Provision for Recently Arrived Refugees in Australia. Melbourne: Australian Housing and Urban Research Institute, Southern Research Centre, 2003; L. Berta. Making it Home. Refugee Housing in. Melbourne's West. Footscray Community Legal Centre. Melbourne: Footscray Community Legal Centre, 2012.

${ }^{73}$ Ibid

${ }^{74}$ Ibid, 25, 28.

75 G. Hugo “A Significant Contribution”, 157.

${ }^{76}$ J. Forrest, K. Hermes, R. Johnston and Poulsen, M. "The Housing Resettlement Experience of Refugee Immigrants to Australia. Journal of Refugee Studies, 2012, doi:10.1093/jrs/fes020.

${ }^{77}$ C. Ransley and S. Drummond Young People, Cultural Diversity and Homelessness: Discussion Paper 1/2000. Melbourne: Centre for Multicultural Youth Issues for the Workers for Real Access To Housing (WRATH) Working Group, 2000; L. Coventry, C. Guerra, D. Mackenzie, and S. Pinkney Wealth of All Nations: Identification of Strategies to Assist Refugee Young People in Transition to Independence. Hobart: A report to the National Youth Affairs Research Scheme, Australian Clearinghouse for Youth Studies, 2002; A. Beer \& P. Foley "Housing Need"; ASRG "Settlement outcomes”; J. Flanagan Dropped From the Moon: The Settlement Experiences of Refugee Communities in Tasmania. Hobart: Social Action and Research Centre, Anglicare, 2007; J. Forrest et. al.“The Housing Resettlement” 
history/referees and identification, and discrimination from landlords and real estate agents; difficulty housing large families; and the inflated Australian real estate market.

No data is collected on the number of refugees and humanitarian entrants on public housing waiting lists. However, evidence suggests that when faced with primary homelessness (i.e., not having a roof over one's head) humanitarian entrants will often stay with friends or family, resulting in overcrowding, family conflict and high levels of stress. ${ }^{78}$ A tragic instance of the difficulties faced in the housing market occurred recently when the 4 year old child of an African refugee family was mauled to death by a neighbour's dog. The family had been staying with another refugee family as their house had burned down. ${ }^{79}$

\section{Health dimensions of settlement}

Both physical and health issues are known to be significant for proportions of the refugee population. Humanitarian entrants are generally in poorer physical health on arrival, despite health checks on acceptance to Australia (although those coming through the onshore program go through slightly less rigorous checks) ${ }^{80}$ It is not our intention to review all physical health issues here, but to highlight some key areas in which research has been undertaken.

Sexual health among young people is a specific area of concern that has been the focus of some research. ${ }^{81}$ Findings suggest that young people from refugee backgrounds are disadvantaged in relation to access to sexual health information and have very little knowledge of sexual health or sexually transmitted diseases (STIs) apart from HIV/AIDS. Barriers to learning about sexual health include concerns about confidentiality, shame, and the competing demands of resettlement. Action research projects indicate that young people from refugee backgrounds can develop stronger mental health and improved sexual health

\footnotetext{
78 J. Flanagan "Dropped From the Moon"

${ }^{79}$ P. Akerman, “'They Didn't Try to Help' As Dog Attacked Child.” The Australian 19 August 2011.

${ }^{80}$ S. Richardson, Stack, M. Moskos, L. Lester, J. Healy, L. Miller-Lewis, D. Ilsley, and J. Horrocks The Changing Settlement Experience of New Migrants: Inter-Wave Comparisons for Cohort 1 and 2 the LSIA. (Report to the Department of Immigration and Multicultural and Indigenous Affairs). Canberra: Commonwealth of Australia, 2004.

${ }^{81}$ S. Gifford et. al.“Good Starts”; P. Gwatirisa Points of Departure Project: National Issues for Immigrant and Refugee Women: Discussion Paper. Melbourne: Multicultural Centre for Women’s Health, 2009; C. McMichael, Promoting Sexual Health Amongst Resettled Youth With Refugee Backgrounds. Melbourne: Refugee Health Research Centre, La Trobe University, 2008; C. McMichael and S. Gifford “'It is Good to Know Now...Before it's Too Late’: Promoting Sexual Health Literacy Amongst Resettled Young People With Refugee Backgrounds." Sexuality and Culture 13, 2009, 218-236; C. McMichael and S. Gifford "Narratives of Sexual Health Risk and Protection Amongst Young People From Refugee Backgrounds in Melbourne, Australia.” Culture, Health and Sexuality 12(3), 2010 263-277.
} 
using targeted creative approaches. ${ }^{82}$

Similar results have been found regarding access to general health care services for women. For example, Drummond and colleagues recently found that issues such as shame or fear of what family and friends might think, of being judged by the treatment provider, of hospitalisation, and logistical difficulties, were significant impediments. ${ }^{83}$

Refugee children and young people face additional health challenges including high rates of infectious diseases; incomplete immunisation; growth and nutrition problems and poor dental health. Research suggests that they have multiple risk factors for educational disadvantage and may have unrecognised developmental delay and disability. ${ }^{84}$

In terms of mental health, two consistent risk factors are linked to mental disorders in refugees: past trauma and post-migration stress. ${ }^{85}$ Settlement difficulties are seen by communities as compounding and contributing to mental health issues - in a study of understandings of depression among a number of refugee communities Fozdar found that settlement issues such as employment, language, housing, loneliness, culture shock, intergenerational and gender role issues, and racism were identified by communities as the causes of depression, in many cases to the exclusion of pre-arrival traumatic experiences. ${ }^{86}$ There is a trend toward increasing problems after arrival. ${ }^{87}$ However, a focus on mental health and trauma may limit appropriate responses to refugee settlement issues. ${ }^{88}$ ColicPeisker and Tilbury for example, argue that settlement services and approaches that focus on trauma can influence refugees to adopt a passive role in their settlement, rather than empower

${ }^{82}$ E.g., S. Gifford “A Good Start”; C. McMichael, "Promoting Sexual Health”

${ }^{83}$ P. Drummond, A. Mizan, K. Brocx, and B. Wright "Barriers to Accessing Health Care Services for West African Refugee Women Living in Western Australia.” Health Care for Women International 32, 2011, 206 224.

${ }^{84}$ N. Davidson, S. Skull, D. Burgner, P. Kelly, S. Raman, D. Silove, Z. Steel, R. Vora, and M. Smith “An Issue of Access: Delivering Equitable Health Care for Newly Arrived Refugee Children in Australia.” Journal of Paediatrics and Child Health 40, 2004, 569-575.

${ }^{85}$ D. Silove and S. Ekblad 2001 "How Well Do Refugees Adapt After Resettlement in Western Countries?” Acta Psychiatrica Scandinavica 106(6), 2001, 401-402.

${ }^{86}$ F. Tilbury "I Feel I am a Bird without Wings"; F. Fozdar "The Golden Country”

${ }^{87}$ R. Schweitzer, F. Melville, Z. Steel, and P. Lacherez "Trauma, Post-migration Living Difficulties, and Social Support as Predictors of Psychological Adjustment in Resettled Sudanese Refugees." Australian and New Zealand Journal of Psychiatrists 40, 2006, 179-187.

${ }^{88}$ F. Tilbury et. al."Listening to Diverse Voices”; V. Colic-Peisker and F. Tilbury ““Active' and 'Passive' Resettlement: The Influence of Support Services and Refugees' own Resources on Resettlement Style”. International Migration, 41(5), 2003, 61-91; F. Tilbury “'I feel I am a bird without wings”: discourses of sadness and loss among east Africans in Western Australia”, Identities: Global Studies in Culture and Power, 14 (4), 2007, 433 - 458; P. Westoby “Developing a Community-Development”; J. Marlowe "Beyond the Discourse of Trauma: Shifting the Focus on Sudanese Refugees.” Journal of Refugee Studies 23(2), 2010, 183198 
them to lead self-sufficient lives. ${ }^{89}$ This reinforces the current approach to settlement service delivery which tends to use a "therapeutic state-centric response". ${ }^{90}$ Indeed the degree to which research and service provision targets mental health has been criticized for pathologising refugees to Australia. ${ }^{91}$

An increased focus on resettlement issues and post-migration stressors is apparent in recent research, however, marking a shift away from the earlier focus on pre-migration trauma. This research has shown that post-migration stressors can have a significant impact on settlement outcomes. One study with Tamil asylum-seekers, refugees and immigrants in Australia found that while pre-migration trauma exposure accounted for some post-traumatic stress symptoms (20 per cent of the variance), so too did post-migration stress (14 per cent of the variance). ${ }^{92}$ Clearly addressing post-migration stressors should be an important aspect of interventions.

Research in Australia has also found particular impacts on women. Ferguson and Pittaway explored the emotional and mental health experiences of women refugees in Australia and found that issues around gender inequalities, sexual assault, marital experiences and female genital mutilation, are prevalent, yet often remain invisible due to their sensitivity. ${ }^{93}$ While many refugee children display remarkable resilience and adaptability, mental health problems such as depression, anxiety and posttraumatic disorder are prevalent and often persistent. ${ }^{94}$

In terms of service provision, the Australian health system has been aware of the need for culturally sensitive health provision for many years yet research continues to show that

\footnotetext{
${ }^{89}$ V. Colic-Peisker and F. Tilbury “'Active' and 'Passive’ Resettlement”

${ }^{90}$ Rajaram, K. "Humanitarianism and representations of the refugee”. Journal of Refugee Studies. 15, 2002, 247; see also V. Colic-Peisker and F. Tilbury “'Active’ and 'Passive’ Resettlement”; C. Fisher “The Exploration of the Nature”; F. Fozdar and S. Torezani "Discrimination and Wellbeing”

91 F. Fozdar "The Golden Country”; J. Marlowe "Beyond the Discourse of Trauma”; J. Matthews "Schooling and Settlement"; F. Tilbury "I Feel I am a Bird without Wings"

92 Z. Steel, D. Silove, K. Bird, P. McGorry, and P. Mohan "Pathways From War Trauma to Posttraumatic Stress Symptoms Among Tamil Asylum Seekers, Refugees, and Immigrants.” Journal of Traumatic Stress 12(3), 1999, 421-35.

${ }^{93}$ B. Ferguson and E. Pittaway Nobody Wants to Talk About It: Refugee Women's Mental Health. Parramatta, NSW: Transcultural Mental Health Centre, 1999.

${ }^{94}$ N. Davidson, S. Skull, D. Burgner, P. Kelly, S. Raman, D. Silove, Z. Steel, R. Vora, and M. Smith “An Issue of Access: Delivering Equitable Health Care for Newly Arrived Refugee Children in Australia.” Journal of Pediatrics and Child Health 40, 2004, 569-575; I. Correa-Velez, S. Gifford, and S. Bice "Australian Health Policy on Access to Medical Care for Refugees and Asylum Seekers." Australian and New Zealand Health Policy 2, 2005, 23-34; S. Raman, N. Wood, M. Webber, K. Taylor, and D. Isaacs "Matching Health Needs of Refugee Children With Services: How Big is the Gap?” Australian and New Zealand Journal of Public Health 33, 2009, 466-470.
} 
this is an ongoing problem. ${ }^{95}$ Research into depression among Horn of Africa and former Yugoslav refugees in Western Australia in the early 2000s indicated perceptions of a lack of culturally appropriate diagnosis and care. ${ }^{96}$ Afghan women of refugee background in the state of Victoria also identified the need for culturally appropriate interventions and diagnostic tools in regard to maternal health and mental health issues. ${ }^{97}$ Indeed, across the whole humanitarian entrant population, there are significant barriers to accessing health care including financial, belief systems, language, an under-trained workforce, and legal and policy issues. ${ }^{98}$ A strong perception of discrimination, miscommunication and poor quality service provision when accessing health and welfare services has also been documented in a diverse group of women from Africa and Middle East. ${ }^{99}$ While resources exist to assist General Practitioners in treating refugees in culturally appropriate ways ${ }^{100}$ it is not known how widely these are used.

\section{Socio-cultural dimensions of settlement}

\subsection{Social support, networks and community engagement}

Reconstituting family and social networks assures emotional and material stability during settlement and is a significant source of comfort. ${ }^{101}$ Connections with the wider Australian community also affect people's sense of well-being, and in addition provide a form of social capital that enables access to knowledge about Australian services and systems, as well as values and cultural practices.

While some research has focussed on the sense of exclusion and marginality that refugees to Australia feel, recent work indicates that for a majority the situation is rather

\footnotetext{
${ }^{95}$ L. Jayasuriya, D. Sang, and A. Fielding Ethnicity, Immigration and Mental Illness: A Critical Review of Australian Research. Canberra: Bureau of Immigration Research, Australian Government Publishing Services, 1992; I. Minas T. Lambert, S. Kostov, and G. Boranga G Mental Health Services for NESB Immigrants: Transforming Policy Into Practice. Canberra, Australian Government Publishing Service, 1996.

${ }^{96}$ F. Tilbury "I Feel I am a Bird without Wings”; F. Tilbury et. al.“Listening to Diverse Voices”; F. Fozdar “The Golden Country”.

${ }^{97}$ A. Rintoul Understanding the Mental Health and Wellbeing of Afghan Women in South East Melbourne. Melbourne: Department of Health, Monash University, 2010.

98 E.g., R. Feldman "Primary Health Care for Refugees and Asylum Seekers: A Review of the Literature and a Framework for Services.” Public Health, 120(9), 2006, 809-816.

99 P. Allotey and L. Manderson "From Case Studies to Casework: Ethics and Obligations in Research With Refugee Women. In The Health of Refugees: Public Health Perspectives From Conflict to Settlement. Ed. P. Allotey. Melbourne: Oxford University Press, 2003, 200-211; P. Allotey, L. Manderson and S. Grover "The Politics of Female Genital Surgery in Displaced Communities.” Critical Public Health 11(3), 2001, $189-201$. 100 E.g., Foundation House Promoting Refugee Health: A Guide for Doctors and Other Health Care Providers Caring for People From Refugee Backgrounds. Melbourne: Foundation House, 2007; NDGP “GP Kit of Refugee Resources”. Northern Division of General Practitioners. Melbourne, 2008, available at: http://www.ndgp.org.au/gp-kit-of-refugee-health-care-resources/w1/i1001431/ (last visited 13 Sept. 2011)

${ }^{101}$ M. Brough et. al."Young Refugees Talk about Well-Being”'.
} 
rosier. In terms of a sense of connection to the local community the SONA survey found over half of humanitarian entrants felt well connected, and another 38 per cent a little connected, proportions comparable to other visa category entrants. ${ }^{102}$ On arrival, only a quarter of humanitarian entrants do not have family or close friends living in Australia, indicating that a majority have a support network from which they can draw immediately. ${ }^{103}$ Sixty per cent agreed or strongly agreed that they felt part of the mainstream of Australian social and cultural life. $^{104}$

Hugo found that settlers from humanitarian backgrounds are among the most spatially concentrated of Australia's migrant populations. He attributes this to their being settled by service providers in areas close to compatriots and necessary services. ${ }^{105}$ There is also likely to be a socio-economic effect - more recent arrivals tend to concentrate in more affordable areas with housing of the type required for their family size. This results in local social connections.

In terms of local neighbourhood networks Hugo found three quarters of his respondents reported having strong networks of friends in the neighbourhood, with only 1.4 per cent not mixing with neighbours. ${ }^{106}$ Ninety-five per cent participated in community activities such as local events, playgroups, religious services, school events, attending local parks and the library. ${ }^{107}$ In terms of the types of activities engaged in, the SONA study found that humanitarian entrants participate in religious groups and cultural groups at much higher levels than family or skill stream entrants (61 per cent versus 28 per cent and 31 per cent respectively; and 46 per cent versus 22 per cent and 19 per cent respectively). ${ }^{108}$

Refugees also participate in ethnic community activities at high levels - Hugo's survey found that only 3.7 per cent do not participate in religious services, festivals, community events or meetings. ${ }^{109}$ Humanitarian settlers provide significant assistance to others in their communities including loaning household items, providing transport, assisting with shopping, meals, childcare or with loans. Less than 10 per cent had provided no assistance. $^{110}$

\footnotetext{
${ }^{102}$ ASRG "Settlement Outcomes of New Arrivals", 43.

${ }^{103}$ Ibid, 42.

${ }^{104}$ Ibid, 43.

${ }^{105}$ G. Hugo “A Significant Contribution”, 84.

${ }^{106}$ Ibid, 230.

${ }^{107}$ Ibid, 233.

${ }^{108}$ ASRG "Settlement Outcomes of New Arrivals", 43.

${ }^{109}$ G. Hugo “A Significant Contribution”, 228.

${ }^{110}$ Ibid, 227.
} 
Material and emotional connections with those remaining in their countries of origin are also high. Despite being the poorest section of the migrant population, refugees are the most likely to send remittances, contributing significantly to poverty reduction in their countries of origin. ${ }^{111}$

These internal and external connections produce a sense of belonging and improve well-being. A number of studies indicate that refugees are generally satisfied with their lives in Australia, showing that a majority are happy. Hugo, for example, reports around 87 per cent agree or strongly agree that they are happy with their lives in Australia, slightly higher than the 77 per cent found among educated refugees by Fozdar and Torezani. ${ }^{112}$ While satisfaction is high however, levels of comfort are somewhat lower for humanitarian entrants (57 per cent), than for family (80 per cent) and skilled (82 per cent) entrants. ${ }^{113}$

A key feature of refugee communities as they become established, is a formalisation of volunteer work that members undertake to assist their compatriots in the settlement process. Rather than seeing this as 'volunteering', it is understood as a community obligation. ${ }^{114}$ Therefore, while the level of reported voluntary work in the 2006 census was lower for humanitarian entrants than the general population, this is likely due to significant under-reporting. ${ }^{115}$ Indeed, the SONA report found that almost 20 per cent of humanitarian settlers contributed to community or family work, and Hugo's survey indicates close to 60 per cent have volunteered. ${ }^{116}$ Voluntary work may consist of informal assistance provided to family and community members, or more formal work associated with community organizations. A common complaint from refugees is burn-out due to the high demands on their time both from their own communities and those service providers and organizations desiring to assist them, and by researchers.

Difficulties around applications for family reunification remain a significant issue. The UNHCR promotes reunification as a component of restoring and preserving refugees' lives; however, this requires appropriate legislative measures. ${ }^{117}$ Australian immigration law allows family reunion, but refugees frequently note problems in terms of definitions of

\footnotetext{
111 Ibid, 203.

${ }^{112}$ G. Hugo “A Significant Contribution”, 245; F. Fozdar and S. Torezani “Discrimination and Wellbeing”, 43.

113 G. Hugo “A Significant Contribution”, 246.

114 Ibid, 217.

${ }^{115}$ RCOA 2009 “Australia’s refugee and humanitarian program”.

${ }^{116}$ G. Hugo “A Significant Contribution”, 224.

${ }^{117}$ UNHCR “Refugee Resettlement”.
} 
'family' and proof requirements. ${ }^{118}$ The restrictions on family reunion are suffered in particular by women. In a study of Somali women in Melbourne, family separation was found to be a significant source of anxiety and sadness. Loneliness and depression among these women centred around feelings of not belonging, and not having family nearby for support. ${ }^{119}$ In another study of resettled Sudanese refugees, concern about family not living in Australia was found to be the most common issue associated with depression, anxiety and somatisation. $^{120}$

A growing problem is the linking of the Special Humanitarian Program, through which family re-unification is enabled, with the Onshore Program for asylum-seekers - for each onshore application approved, a place is lost for existing refugee settlers trying to bring family over. Australia is the only country to link its protection program to its resettlement program. This creates tension between the two programs and a strain on the family reunification quota. ${ }^{121}$

Thus while social networks of support exist for many refugees, issues around family reunion remain a significant source of mental anguish for many.

\subsection{Racism}

Settlement experiences of refugees are clearly linked to the reception they receive in host countries. Prejudice towards refugees among members of the host community presents a significant barrier to resettlement. Australian attitudes toward newcomers have vacillated over the last 100 years, as evidenced in public policy and opinion polls. ${ }^{122}$ Some of this is attributable to the variable wording of opinion poll questions - the Refugee Council of Australia reviewed questions used in opinion polls and found massive differences in results

\footnotetext{
118 F. Tilbury et. al.“Listening to Diverse Voices”; F. Tilbury "I Feel I am a Bird without Wings”; C. Iredale et. al. “Ambivalent Welcome”; B. Ferguson and E. Pittaway "Nobody Wants to Talk About It”.

119 C. McMichael and M. Ahmed “Family Separation: Somali Women in Melbourne.” Refugee Rights Monograph. Melbourne: Deakin University, 2003; see also F. Tilbury and M. Rapley “'There Are Orphans in Africa Still Looking for My Hands': African Women Refugees and the Sources of Emotional Distress." Health Sociology Review 13(1), 2004, 54-64; Hutchinson, H. My Heart Is In Two Places: Ontological Security, Emotions and the Health of African Refugee Women in Tasmania. Unpublished PhD thesis. Hobart: University of Tasmania, 2010.

${ }^{120}$ R. Schweitzer et. al.“Trauma, Post-Migration Living Difficulties”.

121 The Australian government recently announced it was considering changes to delink the programs, but simultaneously, in an attempt to make on-shore applications less attractive, has made access to services for those arriving by boat more difficult.

${ }^{122}$ K. Neumann Refuge Australia: Australia's Humanitarian Record. Sydney: University of New South Wales Press, 2004.
} 
depending on whether the question was worded positively or negatively. ${ }^{123}$ Depending on wording, up to three quarters of Australians are against refugees, or two thirds in favour. For example, a 2006 Lowy Institute poll asked: "Below is a list of possible threats to the vital interest of Australia in the next 10 years. Please say whether you see this as a critical threat, an important but not critical threat, or not an important threat all.” One of the options, "large numbers of immigrants and refugees coming into Australia”, produced 75 per cent agreement that this was a critical or important threat. On the other hand, in a 2003 survey conducted by JOBfutures and Saulwick when asked: "Would you say that over the past two or three years the number of refugees has represented a very serious threat, a quite serious threat, not a very serious threat or no threat at all to the country?”, sixty-one per cent of respondents felt that the number of refugees posed no threat or not a serious threat.

A useful resource is Monash University's inventory of Australian public opinion surveys which tracks large scale polls since 2009 on the topic of immigration, including attitudes to refugees and asylum-seekers. ${ }^{124}$ Of interest is the fact that so few of the polls ask about attitudes to refugees - most demonstrate a degree of negativity among the general population to immigration generally and high degrees of negativity towards asylum-seekers specifically, but do not canvass attitudes towards refugees. One exception is the Lowy Poll (mentioned above) which tracks the increasing perception that migrants and refugees constitute a critical threat to Australia (up from 31 per cent in 2006, to 33 per cent in 2008 and 39 per cent in 2009). In terms of attitudes towards the number of refugees taken, the Essential Report in 2009 found that 62 per cent favour a decrease. However the Scanlon report found that 66 per cent of Australians have a somewhat or very positive feeling towards "refugees who have been assessed overseas and found to be victims of persecution and in need of help coming to live in Australia as permanent or long term residents”. ${ }^{125}$ This wording takes into account the fact that the Australian public is generally unclear about the distinction between asylum-seekers and refugees, which often results in the negativity felt towards asylum-seekers who arrive by boat being transferred to all refugees.

\footnotetext{
${ }^{123}$ RCOA 2008 “Australia’s Refugee and Humanitarian Program”; see also P Power, Australian Attitudes to the Acceptance of Refugees. Summary of speech given to 'Racism Revisited: Anti-racism Leadership and Practice' Conference, Murdoch University, Perth - 20 March 2010, 3-4, available at: http://www.refugeecouncil.org.au/docs/resources/100320_MurdochUniConference.pdf (last visited 30 Sept. 2011).

${ }^{124}$ A. Markus An Inventory of Australian Public Opinion Surveys, 2011, available at: http://arts.monash.edu.au/mapping-population/inventory-of-surveys.php (last viewed 29 July 2011) ${ }_{125}$ A. Markus Mapping Social Cohesion: The Scanlon Foundation Surveys Summary Report. Melbourne: Monash Institute for the Study of Global Movements, 37, 2010, available at: http:/:www.globalmovements.monash.edu.au (last visited 23 Aug. 2011)
} 
Negativity towards refugees often manifests in racism, which occurs in both personal and institutional forms. Simply being a humanitarian entrant, but also having some form of visible difference from the mainstream, such as coming from an African or Muslim background, sometimes results in personal experiences of exclusion. ${ }^{126}$ In terms of institutional racism, in a West Australian study of employers’ perceptions of issues faced by refugees, Tilbury and Colic-Peisker found that while many employers had a degree of goodwill toward migrants and refugees and recognised that they face barriers in the employment market, they also almost universally denied the existence of discrimination in the Australian workplace and employment market. ${ }^{127}$ At the same time, the employers admitted they sometimes discriminated for the sake of their customers or other employees. For example, if customers did not like to see a receptionist in hijab, or workers did not like to work with one, the firm simply could not employ such a person - it was seen as the economically responsible thing to do, clearly ignoring anti-discrimination laws.

Racism is certainly felt by refugees in Australia and seen as a cause of settlement difficulties, who feel both obvious and subtle forms of exclusion, and frequently ask 'at what point am I no longer a refugee and just an Australian’. ${ }^{128}$ A discursive analysis of the ways in which Sudanese refugees deal with the question 'where are you from' illustrates the range of creative responses they use which focus around the assertion of their right to be seen as part of the Australian community. ${ }^{129}$

\subsection{Culture shock (intergenerational disputes and gender role issues)}

Cultural adjustment requires considerable energy in the early stages of resettlement. With recent changes in countries of origin, the ‘cultural gap' between mainstream Australian society and incoming refugees has grown. Refugees point out that they are constantly told that Australia is a multicultural society, but they feel their cultural values and practices are

\footnotetext{
${ }^{126}$ F. Tilbury et. al."Listening to Diverse Voices”; F. Tilbury “I Feel I am a Bird without Wings”; C. Iredale et. al. “Ambivalent Welcome”; B. Ferguson and E. Pittaway “Nobody Wants to Talk About It”.

${ }^{127}$ F. Fozdar and Colic-Peisker "Deflecting Responsibility"

${ }^{128}$ F. Fozdar et. al."Listening to Diverse Voices”; V. Colic-Peisker and F. Tilbury "Integration into the Australian Labour Market”; I. Correa-Velez et. al."Longing to Belong”; S Dhanju 2009 "Welcome or Unwelcome”; C. Iredale, C. Mitchell, R. Pe-Pau, and E. Pittaway Ambivalent Welcome: The Settlement Experiences of Humanitarian Entrant Families in Australia. Canberra: Department of Immigration and Ethnic Affairs, 1996; ROCA 2009 “Australia’s Refugee and Humanitarian Program”

${ }^{129}$ A. Hatoss "Where are you from? Identity construction and experiences of 'othering' in the narratives of Sudanese refugee-background Australians.” Discourse \& Society 23(1), 2012, 47-68.
} 
devalued through a process of 'cultural imperialism'. ${ }^{130}$

When adapting to Australia, many refugees are faced with a sudden loss of identity and the need to reconstruct themselves within the new context. ${ }^{131}$ Individuals and cultural groups vary in the rate and degree to which this process occurs. ${ }^{132}$ This can be a major source of tension and conflict for families, communities and service providers.

Refugees identify this process of transition as a significant challenge, particularly in terms of adapting to changed gender roles within the family where women are encouraged both structurally and interpersonally to be independent of their husbands, producing gender conflict, and where offspring are not only encouraged to be independent but also frequently have more opportunities for rapid integration in terms of language learning, schooling and the development of social networks, resulting in intergenerational conflict. ${ }^{133}$ This causes significant stress, particularly to men, and is identified as the reason for some of the interactions refugees have with the Australian legal system, as it sometimes manifests as violence. One feature of the intergenerational conflict is to do with questions of identity, with parents wanting young people to retain their former cultural identity, and young people focussing more on dual integrated identities. For example, Rodriguez-Jimenez and Gifford's study into young refugees from Afghanistan, Somalia and Sudan, found that young refugees' identity orientations are different from their parents, not being focussed on ethnicity and religion. ${ }^{134}$

Being part of a supportive family has been found to be a key factor in positive resettlement for refugee youth. ${ }^{135}$ At the same time, intergenerational issues and loss of trust, discipline and attachment can pose a serious threat to the family unit. Interestingly, refugee

\footnotetext{
${ }^{130}$ F. Fozdar 2009 “The Golden Country; F. Tilbury “I Feel I am a Bird without Wings”; F. Tilbury et. al."Listening to Diverse Voices"; J.M. Marlowe "Walking the Line: Southern Sudanese masculinities and reconciling one's past with the present”, Ethnicities 9(2), 2011, 1-17.

${ }^{131}$ V. Colic-Peisker and I. Walker "Human Capital, Acculturation and Social Identity: Bosnian Refugees in Australia”. Journal of Community and Applied Social Psychology 133, 2003, 37-360.

${ }^{132}$ R. Sonderegger and P. Barrett "Patterns of Cultural Adjustment Among Young Migrants to Australia." Journal of Child and Family Studies 13(3), 2004, 341-356.

${ }^{133}$ F. Tilbury et. al.“Listening to Diverse Voices”; F. Tilbury “I Feel I am a Bird without Wings”; F. Fozdar “The Golden Country; Gifford et. al.“Good Starts for Recently Arrived Youth”; I. Correa-Velez et. al.“Longing to Belong"; R. Atwell, S. Gifford, and B. McDonald-Wilmsen "Resettled Refugee Families and Their Children’s Futures: Coherence, Hope and Support.” Journal of Comparative Family Studies 40(5), 2009, 677697.

${ }^{134}$ A. Rodriguez-Jimenez and S. Gifford “'Finding Voice’: Learnings and Insights From a Participatory Media Project With Recently Arrived Afghan Young Men With Refugee Backgrounds.” Youth Studies Australia 29(2), 2010, 33-41.

${ }^{135}$ I. McMichael, C., Gifford, S.M. \& Correa-Velez, I. "Negotiating Family, Navigating Resettlement: Family Connectedness Amongst Resettled Youth with Refugee Backgrounds”. Journal of Youth Studies 14(2), 2011,179-195.
} 
children and adolescents in Australia who have the most positive attitudes towards both their culture of origin and Australian culture have the highest ratings of self-worth and peer social acceptance. $^{136}$

\section{Spatial dimensions of settlement}

Where refugees settle is an important aspect of their experience as it can influence access to work opportunities, settlement services, and the ability to interact with people who speak the same language and have similar cultural and religious backgrounds. ${ }^{137}$ While humanitarian settlers are reasonably evenly distributed in Australia, Hugo found that they have settled disproportionally in New South Wales, Victoria, Western Australia, South Australia and the Northern Territory. ${ }^{138}$ Australia is a highly urbanised country, with the vast majority of its population living in the major capital cities. This affects patterns of refugee settlement. Additionally, as noted, there tends to be a concentration of refugees in certain suburbs as a result of settlement service imperatives, socio-economic influences and family and social networks. The overriding trend has been for most refugees to settle in major Australian cities, particularly Melbourne and Sydney. ${ }^{139}$ There have also been increasingly dispersed patterns of settlement in urban metropolitan areas motivated by a number of factors including a general trend towards outer-suburban growth and the limited availability of appropriate affordable housing in the inner-city areas. ${ }^{140}$ These changes in settlement patterns highlight the need for adaptive approaches to service provision. A report based on research in the ruralurban areas of outer Sydney (an area experiencing significant disadvantage and deprivation) accepted that service delivery should vary across regions depending on need. ${ }^{141}$

Although research suggests that newly arrived migrants tend to settle in metropolitan centres near family supports and other social networks and services, there has been a push by the Australian government in recent years to settle humanitarian entrants, and indeed migrants generally, in regional areas of Australia which have seen a reduction in

\footnotetext{
${ }^{136}$ L. Kovacev "Acculturation and Social Support in Relation to Psychosocial Adjustment of Adolescent Refugees Resettled in Australia.” International Journal of Behavioural Development 28(3), 2004, 259-267.

${ }^{137}$ G. Hugo “A Significant Contribution”.

138 Ibid, 90.

${ }^{139}$ Ibid.

${ }^{140}$ VFST Towards a Health Strategy for Refugees and Asylum Seekers in Victoria. Melbourne. Report to Victorian department of Human Services, 2004.

${ }^{141}$ Macarthur Diversity Services Rural-Urban Settlement in Macarthur and Nepean Regions, 2005, available at: http://www.mdsi.org.au/pub/Research_Report.pdf (last visited 17 Aug. 2011).
} 
population. ${ }^{142}$ Particular initiatives have included grants for humanitarian community services, needs-based planning and improved settlement information in regional areas. The rationale behind the policy is that it will enable humanitarian entrants to contribute to and participate in Australian society as soon as possible after arrival, while simultaneously helping to (re)build regional economies.

Hugo argues that regional centres offer refugees opportunities and benefits that are more difficult to find in large urban centres, such as affordable housing; employment opportunities (although these are usually in low skilled and unpopular jobs) and a smaller community environment which remains appealing for refugees who may have come from similar contexts in their home countries. ${ }^{143}$

However, other research finds that the personal experiences of humanitarian entrants settling in regional areas vary and that there are numerous additional constraints on accessing settlement and related services which both directly and indirectly exclude them from achieving settlement goals. ${ }^{144}$ Johnson, Vasey, and Markovic, for example, found that Iraqi refugees living in a regional town in the state of Victoria had limited employment opportunities despite being professionally qualified, and participants commonly stated that the wages were poor and the type of work demeaning. ${ }^{145}$ In addition, they found English skills difficult to obtain in their local area with English classes stopping altogether, and that access to services in the social and health sectors was limited. It is difficult to determine whether these problems were simply 'teething difficulties' due to the newness of the regional settlement initiative. Other studies have produced mixed results. Correa-Velez and colleagues compared the use of health services of humanitarian entrant men settled in urban compared to

\footnotetext{
142 S. Sypek, G. Clugston, and C. Phillips "Critical Health Infrastructure for Refugee Resettlement in Rural Australia: Case Study of Four Rural Towns.” Australian Journal of Rural Health 16, 2008, 349-354; CVWPM Final Report of the Commonwealth-Victoria Working Party on Migration. Melbourne: Commonwealth-Victoria Working Party on Migration, 2004.

143 G. Hugo “A Significant Contribution”.

${ }^{144}$ E.g., R. Stevenson, Hopes Fulfilled or Dreams Shattered? Background Paper: From Resettlement to Settlement Conference, 23-28 November 2005, available at: http://www.sprc.unsw.edu.au/media/File/Resettlement_service_for_refugee_children.pdf (last visited 13 July 2011); J. Taylor and D. Stanovic Refugees and Regional Settlement: Balancing Priorities. Melbourne: Brotherhood of St. Laurence, 2005; A, Nsubuga-Kyobe and C. Hazelman Diversity Management Strategies: Community Driven Employment: Congolese Experience in Shepparton. Paper prepared for the African Resettlement in Australia 2007 Conference, University of Melbourne, School Law, 11-13 April 2007, available at: http://eccv.org.au/library/doc/CongolesePilotProject.pdf (last accessed 18 September 2011); McDonald, B., S. Gifford, K. Webster, J. Wiseman, and S. Case Refugee Resettlement in Regional and Rural Victoria: Impacts and Policy Issues. Melbourne: Refugee Health Research Centre, La Trobe University, 2008

${ }^{145}$ V. Johnston, K. Vasey and M. Markovic “Social Policies and Refugee Resettlement: Iraqis in Australia”. Critical Social Policy 29, 2009, 191-215.
} 
regional areas. ${ }^{146}$ They found that while participants reported good levels of subjective health and well-being, men living in urban areas were more likely to have a long-standing illness and report poorer health than those settled in regional areas. In contrast, men living in regional areas reported poorer levels of well-being in the environment domain and were more likely to visit hospital emergency departments.

Thus regional resettlement in Australia, while contributing to the economic development of regional towns, may lead to the exclusion of refugees in some domains.

\section{Conclusion}

The literature reviewed reveals a mixed picture of refugee settlement in Australia. Research indicates that while refugees may initially have little cultural capital, they bring with them personal resources of resilience and skills which they have a strong desire to use to their adopted country's benefit. Significant support is provided by government or through government funded services. However several areas remain a problem, including employment, and increasingly housing. For some, English language learning is also an issue - despite service providers' best efforts to ensure this is a priority, the fact that a quarter of humanitarian entrants do not complete the free English classes is a matter of on-going concern. Less material issues such as connections with the wider community and sense of belonging are aspects of settlement that can be worked on by both the refugee communities and the wider Australian community. It is clear from Hugo's research that some of these standard resettlement problems will be resolved over time. This is not to say that the situation cannot be improved, with structural support, but also better community engagement, knowledge and more positive attitudes.

A number of policy recommendations emerge. The tendency to use a deficit model in refugee settlement devalues people and reinforces the view of the mainstream population that refugees are a liability. A shift away from this model to one that focuses on empowerment and harnessing and fostering the building of social networks would improve this. One concrete method by which this could be achieved is through better linking the Humanitarian Settlement Support services provided in the initial stages of settlement, which takes an intensive case work approach, with the Settlement Grants Program, which provides more structured but less individualized assistance. The use of community based volunteers may

\footnotetext{
${ }^{146}$ Correa-Velez, A. Barnett, S. Gifford, and D. Sackey "Health Status and Use of Health Services Among Recently Arrived Men With Refugee Backgrounds: A Comparative Analysis of Urban and Regional Settlement in South-East Queensland.” Australian Journal of Primary Health 17(1), 2011,66-71.
} 
also assist with the development of more 'natural' social networks between refugees and the wider community, obviating the need for extensions of formal service provision. Another problem is the lack of coordination between service providers. The competitive funding model works against coordination of service provision, encouraging a fragmented rather than holistic approach. It also does not encourage long term investment in the sector nor the development of institutional knowledge that would ensure capacity building and consolidation of knowledge and experience in the area.

A major on-going challenge is to change the attitudes of the wider community toward humanitarian entrants. The widespread negativity of the general population remains a concern, particularly given that the SONA study found that "being treated well by the local community" was among the factors that best predicted effective settlement. ${ }^{147}$ Education of the general public and awareness raising campaigns to promote social inclusion would go a long way to improving refugees' sense of being welcomed into the community. While funding for such campaigns exists, the general negativity of media and political discourse tends to override the positive effect such piecemeal campaigns might have. A holistic approach is therefore needed, starting at the top of the political system and integrated into the education system generally, including media training. While useful resources exist to improve media coverage of diversity issues ${ }^{148}$ these appear to have had little impact on media practice. Employer training is also overdue.

While employment is a difficult issue to solve, the challenges of recognising prior skills, training and experience, continue to loom large. Improved access to skills assessment and bridging programs would allow the Australian economy to make better use of its human resources, and also address settlement issues including poverty, mental health issues and social exclusion.

The need to develop adequate English language skills impacts employment, educational opportunities, access to housing, and social connection. It may be that an increase in the number of hours of free English classes is necessary to ensure refugees have adequate levels of English to undertake the work and study they desire, and to engage with other Australians. To improve uptake and retention in the existing program, solutions to barriers such as the need for income from employment (a bonus incentive as part of the current welfare payment

\footnotetext{
${ }^{147}$ ASRG “Settlement Outcomes of New Arrivals”, 1.

${ }^{148}$ See Reporting Diversity Project, 2007, available at: http://www.reportingdiversity.org.au/(last visited 4 Sept 2011).
} 
may be appropriate) and childcare also need to be found.

For young people from refugee backgrounds, given their mental health, physical health, psychosocial and educational needs, there needs to be specific focus in government funded programs.

Finally, consideration of the effects of immigration policies on refugee families is needed. As noted, the Australian immigration system penalizes refugees seeking family reunion by reducing the number of places available under the Special Humanitarian Program by the number of visas granted to those seeking asylum onshore. Given the link between family reunion and positive humanitarian settlement, this is problematic - the programs should be de-linked.

In terms of recommendations for future research, it should be acknowledged that much research has already been undertaken. However, most studies are qualitative and therefore small scale, time limited, and ethno-specific, making generalization difficult. There is a clear need for longitudinal investigations of all aspects of refugee settlement (particularly employment, housing, health, gender differences, and social connections, as well as differences by community). Of particular interest, given that social connections are central to positive re-settlement, would be further exploration of the nature and degree of support that humanitarian entrants receive from, and return to, the local community. Future studies may also benefit from using mixed modes of data collection - although quantitative data is extremely difficult to generate, it is important in order to provide a clear picture of the extent of the various phenomena already identified in qualitative research. With its history of immigration, growing diversity, and policies that support multiculturalism, Australia is an important crucible in which to determine the best ways to ensure positive resettlement of refugees. Ongoing evaluation of existing policies and services, and research that explores the settlement experience more generally, will provide the evidence base necessary to allow modeling of the impact of future refugee intakes and the development of policies to ensure positive outcomes. 